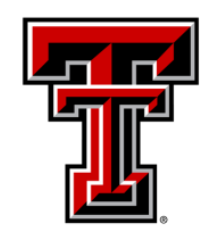

TEXAS TECH UNIVERSITY

Libraries"

\title{
DEPRESSIVE SYMPTOMS AND MULTIMORBIDITY: IS THERE AN ASSOCIATION FOR OLDER BLACK AMERICANS?
}

\section{The Texas Tech community has made this publication openly available. Please share how this access benefits you. Your story matters to us.}

\begin{tabular}{|l|l|}
\hline Citation & $\begin{array}{l}\text { Cho S, Hamler TC. Depressive Symptoms and Multimorbidity: Is } \\
\text { There an Association for Older Black Americans? Journal of Aging } \\
\text { and Health. 2021;33(5-6):310-316. } \\
\text { https://doi.org/10.1177/0898264320981244 }\end{array}$ \\
\hline Citable Link & $\underline{\text { https://hdl.handle.net/2346/86936 }}$ \\
\hline Terms of Use & $\underline{\text { CC BY-NC-ND 4.0 }}$ \\
\hline
\end{tabular}




\title{
DEPRESSION AND MULTIMORBIDITY
}

\section{Depressive Symptoms and Multimorbidity:}

\section{Is There an Association for Older Black Americans?}

\author{
Seungjong Cho, Ph.D. ${ }^{1^{*}}$ and Tyrone C. Hamler, MSW ${ }^{2}$ \\ ${ }^{1}$ Department of Sociology, Anthropology, and Social Work, Texas Tech University \\ ${ }^{2}$ Jack, Joseph and Morton Mandel School of Applied Social Sciences, Case Western \\ Reserve University
}

${ }^{*}$ Corresponding author: Seungjong Cho, 1011 Boston Ave, Lubbock, TX 79409

(email: Seungjong.Cho@,ttu.edu) 


\title{
DEPRESSION AND MULTIMORBIDITY
}

\author{
Abstract \\ Objectives: Many existing studies have reported a higher prevalence of depressive \\ symptoms among older Black Americans. They also experience a disproportionate burden \\ of multimorbidity, the presence of multiple chronic conditions. Therefore, this study was to \\ identify the association between depressive symptomatology and multimorbidity among \\ older Black Americans. \\ Methods: This study analyzed the 2014 Health and Retirement Study $(N=1,206)$. A \\ negative binomial regression was applied to assess the association between multimorbidity \\ and depressive symptomatology. \\ Results: Higher levels of chronic health problems were associated with higher levels of \\ depressive symptomatology among older Black Americans (Incidence Rate Ratio = 1.093; \\ $p=.002)$. Lower self-reported health, lower-income, and lower educational attainment \\ were also related to higher depressive symptoms. \\ Discussion: Older Black Americans experience vulnerability on multiple levels, and \\ shouldering additional psychosocial and financial burdens adds to already established \\ physical health disparities. This requires critical attention from both practice and policy.
}

Keywords: depressive symptoms, chronic diseases, mental health disparities 


\section{DEPRESSION AND MULTIMORBIDITY}

\section{Introduction}

Depressive symptomatology is one of the most prevalent mental health problems in the United States. About 20\% of Americans experience depressive symptoms throughout the course of their lives, a noticeable increase over the last two decades (Gotlib \& Hammen, 2014). Multimorbidity, or the presence of two or more chronic conditions, is a growing issue in medical practice (van den Akker, Buntinx, Roos, \& Knottnerus, 2001). People with multiple chronic conditions face substantial out-of-pocket costs for their care, including higher costs for prescription drugs and increases in overall spending for medical care. Among Medicare fee-for-service beneficiaries, people with multiple chronic conditions account for $93 \%$ of total Medicare spending (Centers for Medicare and Medicaid Services, 2012). Although the relationship between depressive symptoms and chronic conditions has been established among older adults (Huang et al., 2010; Penninx et al., 1998), few studies have explored this association exclusively among older Black Americans. On average, Black Americans are disproportionately burdened by multimorbidity (Baker et al., 2017; Thorpe et al., 2016). To this end, the purpose of this study is to identify the association between chronic health problems and depressive symptoms among older Black Americans using data from the 2014 Health and Retirement Study (HRS). Note that this study does not define depressive symptomatology as a clinical level of disorder given a discrepancy between the high prevalence of depressive symptoms and the comparatively low prevalence of major depressive disorder (Kessler \& Wang, 2008). 


\section{DEPRESSION AND MULTIMORBIDITY}

\section{Depressive Symptoms in the United States}

As researchers and policymakers have increased attention on the impact of mental health, depressive symptoms have emerged as one of the more significant and prevalent mental health problems in the United States. Depression is a significant determinant of quality of life and survival, accounting for nearly half of all psychiatric consultations and $12 \%$ of all hospital admissions (Wang et al., 2017). Depressive symptoms are common in the lives of many individuals. An estimated 1 in 12 individuals in the United States reports having depression (Centers for Disease Control, 2018). The ubiquity of depressive symptoms has been recognized by the US Preventive Services Task Force (USPSTF), which now recommends screening for depressive symptoms in the general adult population (Siu \& USPSTF, 2016). Depression is among the leading causes of disability among individuals in the United States, affecting individuals and families in multiple aspects of their lives. About $80 \%$ of adults with depression reported at least some difficulty with work, home, and social activities because of their depression (Centers for Disease Control, 2018). Furthermore, the global incremental economic burden (including direct medical costs, suicide-related costs, and workplace-related costs) of depressive symptoms on the adult population alone exceeded 210 billion USD in 2010 (Greenberg, Fournier, Sisitsky,

Pike, \& Kessler, 2015). Depression and depressive symptomatology are especially important issues for the older adult population, who often view depressive symptoms as a "normal" part of the aging process. This problem is even more pronounced for older Black American adults who experience higher psychological distress compared to Whites due to lifetime exposure to chronic stressors such as racism, discrimination, poverty, and violence (Pickett, Bazelais, \& Bruce, 2013). 


\section{DEPRESSION AND MULTIMORBIDITY}

\section{Depressive Symptoms among Older Black Americans}

The study of depressive symptoms among older Black American adults is an emerging area of research. Although race and the ways in which racial identity position an individual in a society, and access to social resources have increasingly been acknowledged as crucial components of the social determinants of health, past research has shown paradoxical findings regarding the presence of depressive symptomatology among older Black Americans. Specifically, research has found that older Black Americans experience fewer depressive symptoms than other groups including non-Hispanic whites (Gallo, Patrick \& Lesikar, 1998; Taylor \& Chatters, 2020). Although the prevalence of depressive symptoms is lower among Black Americans than other races, chronicity and severity is higher mainly due to their limited accessibility to appropriate and timely treatment (Chatters, Taylor, Woodward, \& Nicklett, 2015; Taylor, Chatters, \& Nguyen, 2013). Among Older Black Americans, clinically significant depressive symptoms range from $5.4 \%-12.8 \%$ in community samples and $6 \%-33 \%$ in clinical samples (Chatters et al., 2015). Several studies have investigated the connection between depressive symptomatology and these stressors among older Black Americans. Mouzon et al. (2017) found a significant association between depressive symptomatology and everyday discrimination among older Black Americans. Self-esteem and depressive symptoms have been linked among older Black American adults compared to older White adults (Assari, 2017). Using a nationally representative sample, Marshall et al. (2013) compared older

Black Americans and older Caribbean Blacks and found lower educational attainment and lower income were predictive of higher risk for depressive symptoms among the older Black American sample in the study. Several existing studies have reported a higher 


\section{DEPRESSION AND MULTIMORBIDITY}

prevalence of depressive symptoms among older Black American populations (Walsemann, Gee, \& Geronimus, 2009; Williams et al., 2007).

\section{Chronic Diseases in the United States}

Chronic diseases and the presence of multimorbidity are major public health concerns associated with premature death and disability in the United States. Conditions such as heart disease, stroke, cancer, type 2 diabetes, obesity, and arthritis have been recognized as leading causes of death. Approximately, $80 \%$ of individuals over age 65 are diagnosed with multiple chronic conditions (Gerteis et al., 2014). Individuals with multimorbidity are particularly at risk for multiple adverse health-related issues such as complex medication management regimens, burden of self-management and care coordination, and lower rated quality of care. Patients with multimorbidity and concurrent mental health conditions such as depression report lower quality of care compared with patients with physical long-term conditions only (Kang et al., 2015). Data from the Agency

for Healthcare Research and Quality (AHRQ) shows that $71 \%$ of total health care expenditures are associated with care for those with multiple chronic conditions and those diagnosed with at least one chronic medical illness report increased use of health care services compared to those with acute illnesses (Baker et al., 2017).

\section{Chronic Diseases among Older Black Americans}

Racial/ethnic minority groups experience a disproportionate burden of chronic conditions as well as disparities accessing health care and preventive services due to a variety of socioeconomic, behavioral, and other factors (Korda et al., 2013). There are 


\section{DEPRESSION AND MULTIMORBIDITY}

disparities in the onset, course, and prevalence of multiple chronic diseases between Black Americans and other races. Black Americans have higher rates of diseases that can have disabling effects than whites do, as well as less access to high quality health care for those conditions (Thorpe et al., 2016). This problem is of particular concern to older Black Americans who experience cumulative impacts of racism, discrimination and other stressors that impact differential diagnosis and mortality as they relate to multiple chronic diseases. The challenges that older Black Americans face in receiving equitable healthcare treatment has been acknowledged in several previous publications such the National Urban League's (1964) "Double Jeopardy: The Older Negro in America” and the AHRQ's annual National Healthcare Disparities Report, which discuss healthcare access and inequities by race and ethnicity (Wallace, 2015). Despite this knowledge, few studies focus on the impact of chronic disease exclusively among older Black Americans.

\section{Depressive Symptoms and Chronic Diseases}

The presence of increased depressive symptoms are higher among persons with chronic diseases compared with the general population (Huang et al., 2010). The association between higher rates of depressive symptomatology have been examined in several chronic conditions such as stroke (Stek et al., 2004; Tsai, 2007), hypertension (Chen et al., 2007; Tsai et al., 2005), cardiac issues (Gallo et al., 2005; Williams, 2011), diabetes (Anderson, Freedland, Clouse, \& Lustman, 2001; Yu, Zhang, Lu, \& Fang, 2015), and arthritis (Covic et al; 2009; Ziarko, Mojs, Piasecki, \& Samborski, 2014). Read et al. (2017) reported that higher number of chronic health conditions were significantly associated with depression and depressive symptoms in their meta-analysis of 40 articles. 


\section{DEPRESSION AND MULTIMORBIDITY}

Few studies have explored the association between depressive symptoms and chronic diseases among older Black Americans in community settings (e.g., Walker-Taylor et al., 2018; Woodward, Taylor, Abelson, \& Matusko, 2013). Furthermore, most studies have focused on only one disease or a particular combination of diseases. This study examines the association between the number of chronic diseases and depressive symptoms among a nationally representative sample of older Black Americans. Based on the results of previous studies, it is anticipated that the presence of multiple chronic diseases will be associated with higher levels of depressive symptoms. The preceding evidence illustrates that there are knowledge gaps in research on depression and depressive symptoms among older adults and Black Americans.

\section{Methods}

\section{Data}

This study used public data from the 2014 Health and Retirement Study (HRS, 2014). Respondents were interviewed between March 2014 and April 2015. The HRS is a survey with a national probability sample of adults over the age of 50 (Sonnega, Faul, Ofstedal, Langa, Phillips, \& Weir, 2014). The HRS oversampled racial/ethnic minorities (Juster \& Suzman, 1995). The current study analyzed a subsample of older (age $\geq 65$ ) Black Americans $(N=1,206)$. This final sample only included those who answered on every study variables.

\section{Measures}

The outcome of this study is depressive symptomatology. The HRS used a modified 


\section{DEPRESSION AND MULTIMORBIDITY}

short version of the Center for Epidemiologic Studies-Depression (CES-D) scale (Andresen, Malmgren, Carter, \& Patrick, 1994). This measure had eight questions measuring the presence $(1=$ yes or $0=$ no) of depressive symptoms that respondents experienced during the past week (felt depressed, everything was an effort, restless sleep, happy, felt lonely, enjoyed life, felt sad, and could not get going). The depressive symptoms outcome was generated by reverse coding the positively worded items (happy and enjoyed life) and summing the eight items (possible range $=0-8$ ). This measure was reliable (Cronbach's alpha $=.787)$.

Chronic diseases were measured by asking whether respondents had ever been diagnosed with the following seven diseases: high blood pressure, diabetes, cancer, lung disease, heart disease, stroke, and arthritis (possible range $=0-7$ ). Sociodemographic covariates included self-reported health $(1=$ poor to $5=$ excellent $)$, age, gender $(0=$ male $)$, income (logged), marital status $(0=$ not married or partnered $)$, and educational attainment (possible range $=1-17$, where 17 represents 17 years or more).

\section{Analysis Strategy}

This study applied the cross-sectional research design because of the periodic or episodic nature of the outcome measure, which asked the presence of depressive symptoms in the past week. As a preliminary data screening, all study variables were examined for their adequate variability and univariate-level outliers (i.e., $z> \pm 3.30$ on interval-level predictors; Warner, 2013, p. 153). Also, the normal distribution of all interval-level variables was examined by values of skewness $(<|2.00|$ indicating normal distribution $)$ and kurtosis $(<|7.00|)$ using the criteria by Curran, West, and Finch (1996). Bivariate 


\section{DEPRESSION AND MULTIMORBIDITY}

correlation analyses were used to check multicollinearity of the study variables $(<.80$ indicating no multicollinearity; Pett, Lackey, \& Sullivan, 2003, p. 87).

Depressive symptomatology was a count variable, which is numerical but not continuous variable because it "takes on discrete values reflecting the number of occurrences of an event" (Coxe, West, \& Aiken, 2009, p. 121). Consequently, using the ordinary least squares (OLS) regression may not be appropriate with the count outcome of this study since this outcome violates the normal distribution assumption of OLS regression (Long, 1997). Instead, a negative binomial regression was applied to assess the association between chronic diseases and depressive symptomatology using Stata 14.2. Among the various statistical techniques to available to analyze the count variable, this study chose negative binomial regression model due to (a) the depressive symptomatology was a count and skewed variable with a number of zeros and relatively fewer higher values (Long, 1997). In addition, since the standard deviation of depressive symptomatology (1.95) was larger than its mean (1.55) the current study expected overdispersion (Long, 1997). All predictors were entered simultaneously.

\section{Results}

\section{Preliminary Analysis}

This study tested univariate distributions and bivariate relationships of the key study variables. Table 1 summarizes the detailed sample characteristics, and Table 2 shows the bivariate correlations of study variables. In sum, the average number of depressive symptoms of the study participants was $M=1.55(S D=1.95$, Min-Max $=0-8)$, and the average number of chronic diseases was $M=2.74(S D=1.29$, Min-Max $=0-7)$. The 


\section{DEPRESSION AND MULTIMORBIDITY}

average age of the study participants was 75 years old (Min-Max $=66-104)$, and $63.3 \%$ of this sample was female. Only a little over $40 \%$ of the study participants were married or partnered, which is an important demographic aspect of the study. There was no severe multicollinearity between study variables at the bivariate level, and the highest correlation was between income and marital status $(r=.47, p<.001)$. The correlation coefficient between depressive symptoms and chronic diseases was $r=.21(p<.001)$.

\section{Negative Binomial Regression Analysis}

The negative binomial regression model was statistically significant (Wald $\chi^{2}=$ 215.19, $p<.001$ ). Pseudo $R^{2}$ was .052 . The over-dispersion parameter (alpha) was not zero (alpha $=.661, p<.001$ ), which supported the appropriateness of using the negative binomial regression model. The model showed that higher numbers of chronic health problems were associated with higher levels of depressive symptomatology among older Black Americans (Incidence Rate Ratios [IRR] $=1.093 ; p=.002$ ). For each additional chronic health problem, the rate for depressive symptoms would be expected to increase by a factor of 1.093 when the other predictors in the model are held constant. Among the covariates, self-reported health $(I R R=.715 ; p<.001)$, logged income $(I R R=.827 ; p<$ $.001)$, and educational attainment $(I R R=.946 ; p<.001)$ were significant. Compared to men, women were expected to have a rate of 1.156 times greater for depressive symptoms, but this finding was not significant $(p=.065)$. Table 3 shows the detailed negative binomial regression analysis results. 


\section{DEPRESSION AND MULTIMORBIDITY}

\section{Discussion}

This study explores the relationship between physical and mental health among older Black Americans. Respondents reported a significant relationship between more chronic health conditions and higher depressive symptomatology supporting previous studies (reviews by Anderson et al., 2001; Huang et al., 2010; Read et al., 2017). This study shows similar findings of the few empirical studies of the relationship between depressive symptomatology and multimorbidity for Black Americans (e.g., Williams, 2011). Older Black Americans experience vulnerability on multiple levels, and shouldering additional psychosocial and financial burdens add to already established physical health disparities. The finding of this study requires critical attention from professional practice. While managing the physical needs of people living with multimorbidity, practitioners should consider the effects of multimorbidity on depressive symptomatology. Depression and chronic illness together are drivers that increase healthcare costs and have developed into a critical problem for the older adult population.

The findings from this study suggest that bolstering supports and the use of social services may have a significant impact on how older Black Americans manage multimorbidity and depressive symptomatology (Neighbors et al., 2008; Ward et al., 2013). In previous studies, social support has been demonstrated to be an important factor in the presence of depressive symptomatology among older Black Americans (Chatters et al., 2015). Combined with the results of the current investigation there are implications for future studies that suggest social support may be a protective factor in this population. A nuanced conceptualization of social support is necessary to account for the ways in which older Black Americans have learned to adapt and survive in care systems that have always 


\section{DEPRESSION AND MULTIMORBIDITY}

been designed to treat or care for Black Americans. Therefore, the support of additional social services may prove to be quite valuable in this population.

The utilization of social services in this population may aid in disease management, health care access and utilization, and the ability to mobilize social resources to provide needed support. Engagement with professions and organizations that provide supportive services for older adults is key for this population. Considering the potential impacts of bolstering social support to access social resources and the impact of services directed at older adults, there is great potential for issues such as multimorbidity and depressive symptomatology to be ameliorated.

This study is not without limitations. The current research only included physical medical conditions (i.e., high blood pressure, diabetes, cancer, lung disease, heart disease, stroke, and arthritis). According to the U.S. Department of Health and Human Services (2010), chronic conditions also include mental illnesses, cognitive impairment disorders, addiction disorders, and developmental disabilities. For example, this study did not include cognitive impairment (e.g., Alzheimer's disease and related dementia), which affects older Black Americans disproportionately (Gamaldo et al., 2010).

According to recent studies (e.g., Read et al., 2017), chronic diseases and depressive symptoms may have a bidirectional relationship. A systematic review by Mezuk et al. (2012) supported this argument, especially in later life. A longitudinal study by Golden et al. (2008) identified the bidirectional association between type 2 diabetes and depressive symptoms. The cross-sectional nature of the current study did not elucidate the causal relationship between the two. In addition, some scholars (e.g., Rost, Nutting, Smith, Elliott, \& Dickinson, 2002) have suggested that depressive symptomatology should be regarded as a chronic disease. For future research, the association between multimorbidity and 


\section{DEPRESSION AND MULTIMORBIDITY}

depressive symptoms may be conceptualized as the relationship between chronic physical and mental health challenges. Older Black Americans continue to struggle to access equitable mental and physical health care services. The reasons for this disparity are quite complex, as a confluence of social factors such as access to quality and affordable care and structural factors such as racism and classism work together to limit accessibility to care.

Another limitation was the self-reported nature of multimorbidity and depressive symptoms, (and all the other covariates in this study) which could lead to multiple types of research biases, including recall bias and social desirability bias. Despite these limitations, the present study has some important strengths. This study contributes to the gap in existing knowledge about the relationship between multimorbidity and depressive symptomatology among older Black Americans. 


\section{DEPRESSION AND MULTIMORBIDITY}

\section{References}

Andresen, E. M., Malmgren, J. A., Carter, W. B., \& Patrick, D. L. (1994). Screening for depression in well older adults: Evaluation of a short form of the CES-D. American Journal of Preventive Medicine, 10(2), 77-84. doi: 10.1016/S0749-3797(18)306226

Anderson, R. J., Freedland, K. E., Clouse, R. E., \& Lustman, P. J. (2001). The prevalence of comorbid depression in adults with diabetes: A meta-analysis. Diabetes Care, 24(6), 1069-1078. doi: 10.2337/diacare.24.6.1069

Assari, S. (2017). Association between self-esteem and depressive symptoms is stronger among black than white older adults. Journal of Racial and Ethnic Health Disparities, 4(4), 687-695. doi: 10.1007/s40615-016-0272-6

Baker, T. A., Clay, O. J., Johnson-Lawrence, V., Minahan, J. A., Mingo, C. A., Thorpe, R. J., Ovalle, F., \& Crowe, M. (2017). Association of multiple chronic conditions and pain among older black and white adults with diabetes mellitus. BMC Geriatrics, 17(1), 255. doi: 10.1186/s12877-017-0652-8

Centers for Disease Control and Prevention. (2018). Prevalence of depression among adults aged 20 and over: United States, 2013-2016 (NCHS Data Brief No. 303). Hyattsville, MD: National Center for Health Statistics. Retrived from https://www.cdc.gov/nchs/products/databriefs/db303.htm

Centers for Medicare and Medicaid Services. (2012). Chronic conditions among Medicare beneficiaries, Chartbook. Baltimore, MD: Centers for Medicare and Medicaid Services. 


\section{DEPRESSION AND MULTIMORBIDITY}

Chatters, L. M., Taylor, R. J., Woodward, A. T., \& Nicklett, E. J. (2015). Social support from church and family members and depressive symptoms among older Black Americans. American Journal of Geriatric Psychiatry, 23(6), 559-567.

Chen, R., Wei, L., Hu, Z., Qin, X., Copeland, J. R. M., \& Hemingway, H. (2005). Depression in older people in rural China. Archives of Internal Medicine, 165(17), 2019-2025.

Covic, T., Pallant, J. F., Tennant, A., Cox, S., Emery, P., \& Conaghan, P. G. (2009). Variability in depression prevalence in early rheumatoid arthritis: A comparison of the CES-D and HAD-D scales. BMC Musculoskeletal Disorders, 10(1), 18.

Coxe, S., West, S. G., \& Aiken, L. S. (2009). The analysis of count data: A gentle introduction to Poisson regression and its alternatives. Journal of Personality Assessment, 91(2), 121-136.

Curran, P. J., West, S. G., \& Finch, J. F. (1996). The robustness of test statistics to nonnormality and specification error in confirmatory factor analysis. Psychological Methods, 1, 16-29.

Gallo, J. J., Bogner, H. R., Morales, K. H., Post, E. P., Ten Have, T., \& Bruce, M. L. (2005). Depression, cardiovascular disease, diabetes, and two-year mortality among older, primary-care patients. American Journal of Geriatric Psychiatry, 13(9), 748755.

Gallo, J. J., Cooper-Patrick, L., \& Lesikar, S. (1998). Depressive symptoms of whites and Black Americans aged 60 years and older. The Journals of Gerontology Series B: Psychological Sciences and Social Sciences, 53(5), P277-P286.

Gamaldo, A. A., Allaire, J. C., Sims, R. C., \& Whitfield, K. E. (2010). Assessing mild cognitive impairment among older African Americans. International Journal of 


\section{DEPRESSION AND MULTIMORBIDITY}

Geriatric Psychiatry, 25(7), 748-755.

Gerteis, J., Izrael, D., Deitz, D., LeRoy, L., Ricciardi, R., Miller, T., \& Basu, J. (2014). Multiple chronic conditions chartbook (AHRQ Publications No, Q14-0038).

Rockville, MD: Agency for Healthcare Research and Quality.

Golden, S. H., Lazo, M., Carnethon, M., Bertoni, A. G., Schreiner, P. J., Diez Roux, A. V., Lee, H. B., \& Lyketsos, C. (2008). Examining a bidirectional association between depressive symptoms and diabetes. JAMA, 299(23), 2751-2759.

Gotlib, I. H., \& Hammen, C. L. (Eds.). (2014). Handbook of depression (3rd ed.). New York, NY: Guilford Press.

Greenberg, P. E., Fournier, A. A., Sisitsky, T., Pike, C. T., \& Kessler, R. C. (2015). The economic burden of adults with major depressive disorder in the United States (2005 and 2010). Journal of Clinical Psychiatry, 76(2), 155-162.

Health and Retirement Study. (2014). HRS 2014 Core, Final Release [Datafile]. Ann Arbor, MI: University of Michigan, Institute for Social Research.

Huang, C. Q., Dong, B. R., Lu, Z. C., Yue, J. R., \& Liu, Q. X. (2010). Chronic diseases and risk for depression in old age: A meta-analysis of published literature. Ageing Research Reviews, 9(2), 131-141.

Juster, F. T., \& Suzman, R. (1995). An overview of the Health and Retirement Study. Journal of Human Resources, 30(Suppl.), S7-S56.

Kang, H., Kim S., Bae K., Kim S., Shin, I., Yoon J., \& Kim J. (2015). Comorbidity of depression with physical disorders: Research and clinical implications. Chonnam Medical Journal, 51, 8-18. doi: 10.4068/cmj.2015.51.1.8 


\section{DEPRESSION AND MULTIMORBIDITY}

Kessler, R. C. \& Wang, P. S. (2008). Epidemiology of depression. In I. H. Gotlib \& C. L. Hammen (Eds.), Handbook of depression (2nd ed.; pp. 5-22). New York, NY: Guilford Press.

Korda, H., Erdem, E., Woodcock, C., Kloc, M., Pedersen, S., \& Jenkins, S. (2013). Racial and ethnic minority participants in chronic disease self-management programs: Findings from the communities putting prevention to work initiative. Ethnicity \& Disease, 23(4), 508-517.

Long, J. S. (1997). Regression models for categorical and limited dependent variables. Thousand Oaks, CA: Sage.

Marshall, G. L., Hooyman, N. R., Hill, K. G., \& Rue, T. C. (2013). Association of sociodemographic factors and parental education with depressive symptoms among older Black Americans and Caribbean Blacks. Aging \& Mental Health, 17(6), 732-737.

Mezuk, B., Edwards, L., Lohman, M., Choi, M., \& Lapane, K. (2012). Depression and frailty in later life: A synthetic review. International Journal of Geriatric Psychiatry, 27(9), 879-892.

Mouzon, D. M., Taylor, R. J., Keith, V. M., Nicklett, E. J., \& Chatters, L M. (2016). Discrimination and psychiatric disorders among older Black Americans. International Journal of Geriatric Psychiatry, 32(2), 175-182. doi: $10.1002 /$ gps.4454

Neighbors, H. W., Woodward, A. T., Bullard, K. M., Ford, B. C., Taylor, R. J., \& Jackson, J. S. (2008). Mental health service use among older African Americans: The National Survey of American Life. The American Journal of Geriatric Psychiatry, $16(12), 948-956$. 


\section{DEPRESSION AND MULTIMORBIDITY}

Penninx, B. W., Guralnik, J. M., Ferrucci, L., Simonsick, E. M., Deeg, D. J., \& Wallace, R. B. (1998). Depressive symptoms and physical decline in community-dwelling older persons. Jama, 279(21), 1720-1726.

Pett, M., Lackey, N., \& Sullivan, J. (2003). Making sense of factor analysis: The use of factor analysis for instrument development in health care research. Thousand Oaks, CA: Sage.

Pickett, Y. R., Bazelais, K. N., \& Bruce, M. L. (2013). Late-life depression in older Black Americans: A comprehensive review of epidemiological and clinical data. International Journal of Geriatric Psychiatry, 28(9), 903-913.

Read, J. R., Sharpe, L., Modini, M., \& Dear, B. F. (2017). Multimorbidity and depression: A systematic review and meta-analysis. Journal of Affective Disorders, 221, 36-46.

Rost, K., Nutting, P., Smith, J. L., Elliott, C. E., \& Dickinson, M. (2002). Managing depression as a chronic disease: A randomised trial of ongoing treatment in primary care. Bmj, 325(934). doi: 10.1136/bmj.325.7370.93414

Siu, A. L., \& the U.S. Preventive Services Task Force (2016). Screening for depression in adults: US Preventive Services Task Force recommendation statement. Jama, $315(4), 380-387$.

Sonnega, A., Faul, J. D., Ofstedal, M. B., Langa, K. M., Phillips, J. W., \& Weir, D. R. (2014). Cohort profile: The Health and Retirement Study (HRS). International Journal of Epidemiology, 43(2), 576-585.

Stek, M. L., Gussekloo, J., Beekman, A. T. F., van Tilburg, W., \& Westendorp, R. G. J. (2004). Prevalence, correlates and recognition of depression in the oldest old: The Leiden 85-plus Study. Journal of Affective Disorders, 78(3), 193-200.

Taylor, R. J., \& Chatters, L. M. (2020). Psychiatric disorders among older Black 


\section{DEPRESSION AND MULTIMORBIDITY}

Americans: Within- and between-group differences. Innovation in Aging, 4(3), 116. doi: $10.1093 /$ geroni/igaa007

Taylor, R. J., Chatters, L. M., \& Nguyen, A. W. (2013). Religious participation and DSM IV major depressive disorder among Black Caribbeans in the United States. Journal of Immigrant Minority Health, 15(5), 903-909. doi: 10.1007/s10903-012-9693-4

Thorpe, R. J., Wynn, A. J., Walker, J. L., Smolen, J. R., Cary, M. P., Szanton, S. L., \& Whitfield, K. E. (2016). Relationship between chronic conditions and disability in Black American men and women. Journal of the National Medical Association, 108(1), 90-98.

Tsai, Y. F. (2007). Self-care management and risk factors for depressive symptoms among Taiwanese institutionalized older persons. Nursing Research, 56(2), 124-131.

Tsai, Y. F., Yeh, S. H., \& Tsai, H. H. (2005). Prevalence and risk factors for depressive symptoms among community-dwelling elders in Taiwan. International Journal of Geriatric Psychiatry, 20(11), 1097-1102.

U.S. Department of Health and Human Services. (2010). Multiple chronic conditions - A strategic framework: Optimum health and quality of life for individuals with multiple chronic conditions. Washington, DC: Department of Health \& Human Services.

van den Akker, M., Buntinx, F., Roos, S., \& Knottnerus, J. A. (2001). Problems in determining occurrence rates of multimorbidity. Journal of Clinical Epidemiology, $54(7), 675-679$.

Walsemann, K. M., Gee, G. C., \& Geronimus, A. T. (2009). Ethnic differences in trajectories of depressive symptoms: Disadvantage in family background, high 


\section{DEPRESSION AND MULTIMORBIDITY}

school experiences, and adult characteristics. Journal of Health and Social Behavior, 50(1), 82-98.

Wang, J., Wu, X., Lai, W., Long, E., Zhang, X., Li, W., Zhu, Y., Chen, C., Zhong, X, Liu, Z., Wang, D., \& Lin, H.. (2017). Prevalence of depression and depressive symptoms among outpatients: A systematic review and meta-analysis. $B M J$ open, 7(8), $\mathrm{e} 017173$.

Ward, E., Wiltshire, J. C., Detry, M. A., \& Brown, R. L. (2013). African American men and women's attitude toward mental illness, perceptions of stigma, and preferred coping behaviors. Nursing Research, 62(3), 185-194.

Warner, R. (2013). Applied statistics: From bivariate through multivariate techniques (2nd ed.). Los Angeles, CA: Sage.

Williams, D. R., Gonzalez, H. M., Neighbors, H., Nesse, R., Abelson, J. M., Sweetman, J., \& Jackson, J. S. (2007). Prevalence and distribution of major depressive disorder in Black Americans, Caribbean blacks, and non-Hispanic whites: Results from the National Survey of American Life. Archives of General Psychiatry, 64(3), 305-315.

Williams, R. B. (2011). Depression after heart attack: Why should I be concerned about depression after a heart attack? Circulation, 123(25), 639-640.

Woodward, A. T., Taylor, R. J., Abelson, J. M., \& Matusko, N. (2013). Major depressive disorder among older Black Americans, Caribbean Blacks, and non-Hispanic Whites: Secondary analysis of the National Survey of American Life. Depression and Anxiety, 30(6), 589-597. doi: 10.1002/da.22041

Yu, M., Zhang, X., Lu, F., \& Fang, L. (2015). Depression and risk for diabetes: A metaanalysis. Canadian Journal of Diabetes, 39(4), 266-272.

Ziarko, M., Mojs, E., Piasecki, B., \& Samborski, W. (2014). The mediating role of 


\section{DEPRESSION AND MULTIMORBIDITY}

dysfunctional coping in the relationship between beliefs about the disease and the level of depression in patients with rheumatoid arthritis. The Scientific World

Journal, 585063. doi: 10.1155/2014/585063 


\section{DEPRESSION AND MULTIMORBIDITY}

Table 1. Sample characteristics $(N=1,206)$

\begin{tabular}{lcc}
\hline & $M(S D), \%$ & Observed Range \\
\hline Number of Depressive Symptoms & $1.55(1.95)$ & $.00-8.00$ \\
Number of Chronic Diseases & $2.74(1.29)$ & $.00-7.00$ \\
Self-reported Health & $2.81(.97)$ & $1.00-5.00$ \\
Age & $75.18(6.48)$ & $66.00-104.00$ \\
Gender (female $=1)$ & $63.3 \%$ & $2.48-13.07$ \\
Income (logged) & $10.11(.92)$ & \\
Marital Status (married/partnered $=1)$ & $40.6 \%$ & $.00-17.00$ \\
& & \\
Educational Attainment & & \\
& & \\
\end{tabular}

Note. Percentages were reported for dichotomous variables when the values were 1; means and standard deviations were reported for continuous variables. 
DEPRESSION AND MULTIMORBIDITY

Table 2. Bivariate correlations of depressive symptoms and predictors $(N=1,206)$

\begin{tabular}{|c|c|c|c|c|c|c|c|c|}
\hline & 1 & 2 & 3 & 4 & 5 & 6 & 7 & 8 \\
\hline $\begin{array}{l}\text { 1. Depressive } \\
\text { Symptoms }\end{array}$ & - & $\begin{array}{l}.21 \\
* * *\end{array}$ & $\begin{array}{l}-.33 \\
* * *\end{array}$ & $\begin{array}{l}.06 \\
*\end{array}$ & $\begin{array}{l}.11 \\
* * *\end{array}$ & $\begin{array}{l}-.23 \\
* * *\end{array}$ & $\begin{array}{l}-.11 \\
* * *\end{array}$ & $\begin{array}{l}-.22 \\
* * *\end{array}$ \\
\hline $\begin{array}{l}\text { 2. Chronic } \\
\text { Diseases }\end{array}$ & & - & $\begin{array}{l}-.37 \\
* * *\end{array}$ & $\begin{array}{l}.10 \\
* * *\end{array}$ & $\begin{array}{l}.08 \\
* *\end{array}$ & $\begin{array}{l}-.10 \\
* *\end{array}$ & -.05 & $\begin{array}{l}-.12 \\
* * *\end{array}$ \\
\hline $\begin{array}{l}\text { 3. Self-reported } \\
\text { Health }\end{array}$ & & & - & $\begin{array}{l}-.09 \\
* *\end{array}$ & $\begin{array}{l}-.07 \\
*\end{array}$ & $\begin{array}{l}.16 \\
* * *\end{array}$ & $\begin{array}{l}.08 \\
*\end{array}$ & $\begin{array}{l}.16 \\
* * *\end{array}$ \\
\hline 4. Age & & & & - & .06 & $\begin{array}{l}-.27 \\
* * *\end{array}$ & $\begin{array}{l}-.25 \\
* * *\end{array}$ & $\begin{array}{l}-.20 \\
* * *\end{array}$ \\
\hline 5. Gender & & & & & - & $\begin{array}{l}-.24 \\
* * *\end{array}$ & $\begin{array}{l}-.35 \\
* * *\end{array}$ & .06 \\
\hline 6. Income & & & & & & - & $\begin{array}{l}.47 \\
* * *\end{array}$ & $\begin{array}{l}.38 \\
* * *\end{array}$ \\
\hline $\begin{array}{l}\text { 7. Marital } \\
\text { Status }\end{array}$ & & & & & & & - & $\begin{array}{l}.12 \\
* * *\end{array}$ \\
\hline 8. Education & & & & & & & & - \\
\hline
\end{tabular}




\section{DEPRESSION AND MULTIMORBIDITY}

Table 3. Negative binomial regression model predicting depressive symptoms $(N=1,206)$

\begin{tabular}{lccc}
\hline Predictors & Coefficients $(S E)$ & $95 \% C I$ & $\begin{array}{c}\text { Incidence } \\
\text { Rate } \\
\text { Ratios }\end{array}$ \\
\hline Chronic Health Problems & $.089(.028)^{* *}$ & $.033-.144$ & 1.093 \\
Gender (female $=1)$ & $.145(.079)$ & $-.009-.299$ & 1.156 \\
Age & $-.005(.005)$ & $-.015-.006$ & .995 \\
Income (logged) & $-.190(.046)^{* * *}$ & $-.280--.099$ & .827 \\
Educational Attainment & $-.055(.012)^{* * *}$ & $-.079--.031$ & .946 \\
Self-rated Health & $-.335(.038)^{* * *}$ & $-.409--.262$ & .715 \\
Marital Status (married $/$ partnered $=1)$ & $-.025(.082)$ & $-.187-.136$ & .975 \\
\hline Intercept & $3.843(.650)$ & $2.569-5.117$ & 46.663 \\
Alpha & $.661(.063)$ & $.548-.798$ & .661 \\
\hline$* p<.05 . * * p<.01 . * * * p<.001$ & & & \\
\hline
\end{tabular}

